\title{
EVOLUÇÃO GEOLÓGICA DO PRECAMBRIANO NA REGIÃO SUDESTE DO ESTADO DE SÃO PAULO
}

\author{
YOCITERU HASUI* e GEORG ROBERT SADOWSKI*
}

\begin{abstract}
The Precambrian zone between the edge of the Parana Basin and the coastal line, through São Paulo, is characterized by the faulted-blocks tectonic style. The blocks were grouped in four assemblages named Jundiaí, São Roque, Paranapiacaba and Costeiro.

The São Roque Assemblage is constituted by the São Roque Group, an ectinitic stratigraphic unity, which is intruded by late-tectonic granitoid bodies. The geological evolution is summarized by a succession of tectonic and cristallization events: 1) pretectonic basic magmatism, 2) regional metamorphism and late-tectonic granitoid magmatism, sinchronous to the principal folding, 3) crenulation and transposition, 4) retrometamorphism.

The Paranapiacaba Assemblage is formed by the Açungui Group, which includes the Pilar Ectinitic Complexe and the Embu Migmatitic Complex, both with granitoid intrusions. The recognized events of tectonism and cristallyzation are: 1) pretectonic basic magmatism, 2) regional metamorphism sinchronous to a recumbent folding not yet very well defined, 3) a second folding and a syntectonic granitoid magmatism, 4) crenulation and transposition, 5) postectonic granitic magmatism and retrometamorphism.

The Costeiro Assemblage, as well as the four nuclei exposed in the Southeastern part of the Paranapiacaba Assemblage, is formed by migmatitic rocks of the Piaçagüera Complex, which we consider as part of the basement of the Brazilian Folded Belt. It suffered migmatizations, partially during the Brazilian Cycle and also postectonic granitic intrusions during that Cycle.

The Jundiai Block is constituted of pre-Brazilian migmatites (Jundiai Complex), intruded by Brazilian postectonic granitic bodies.

The transcurrent fault system began its evolution after the regional metamorphism and was active untill the end of the Brazilian Cycle. It produced the block compartimentation, which suffered some changes after the Silurian under others tectonic regimes.

The geological evolution of the São Roque and Paranapiacaba Assemblages (except for the supposed pre-Brazilian nuclei) was poliphasic and related to the Brazilian Gycle. For the rest, it seems to have been poliphasic and policyclic.
\end{abstract}

INTRODUÇÃo Diversos estudos têm sido apresentados nos últimos anos versando sobre o Precambriano na região de São Paulo. Tais estudos, face à inexistência de mapas adequados, envolveram, numa primeira fase, trabalhos de cartografia geológica, coincidentemente ao nível de 1:100000. Além disso, eles abordam não só a petrografia mas também aspectos petrológicos, estruturais, tectônicos e estratigráficos, já possibilitando traçar-se um esboço da evolução geológica do Precambriano ao longo de uma faixa entre a borda da Bacia do Paraná e o litoral. A apresentação desse esboço constitui objeto desta nota.

A ÁREA FOCALIZADA A Fìg. 1 é um mapa de síntese de uma faixa que se estende da região de Indaiatuba-São Miguel Arcanjo, às bordas da Bacia do Paraná, à região de Santos-Bertioga, no litoral paulista. Essa faixa corresponde a uma seção do Precambriano exposto compreendendo todas as unidades estratigráficas reconhecidas.

A parte oriental foi estudada por Sadowski (1974) e Rideg (1974); a central, por Coutinho (1972) e Hasui et al. (inédito); a ocidental, por Hasui et al. (1969) e Hasui (1973). Uma síntese versando sobre a região a oeste da capital paulista foi apresentada por Hasui

*Departamento de Geologia Geral, Instituto de Geociências, Universidade de São Paulo 


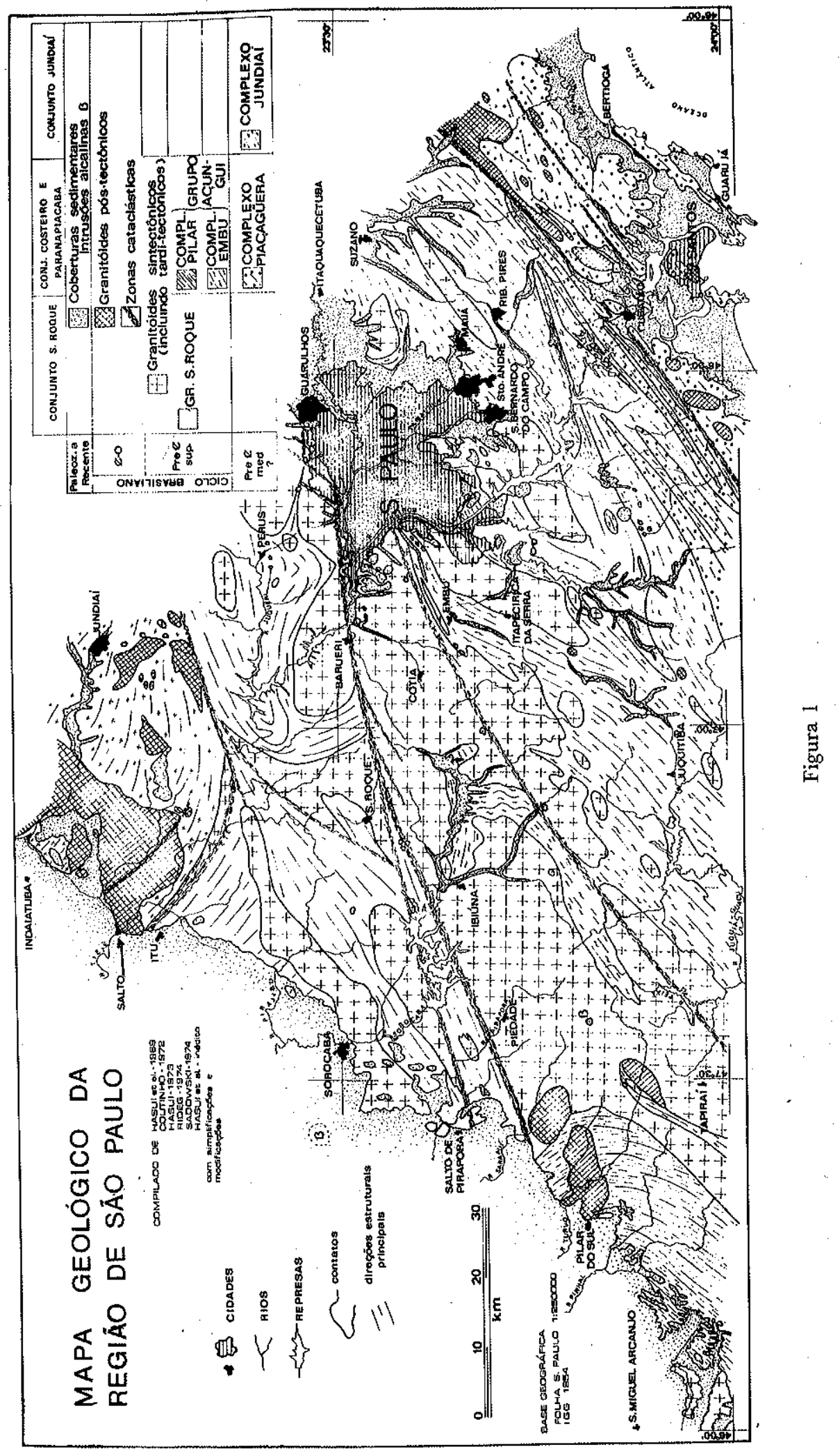


(1975). Numerosos estudos locais foram realizados por diversos autores e boa parte deles será mencionada no texto.

GOMPARTIMENTAÇÃO TEGTÔNICA A característica mais notável do Precambriano na faixa em estudo é a sua compartimentação em blocos justapostos limitados por grandes zonas de falhamento transcorrente. Esse estilo estrutural foi reconhecido pela primeira vez por Hennies et al. (1967), que definiram os Blocos Jundiaí, São Roque e Cotia, separados pelos Falhamentos de Jundiuvira e Taxaquara. Este último foi detallhadamente descrito por Hennies et al. (1967a), e Rideg (1974) o reconheceu estendendo-se até a região de Moji das Cruzes, o que lhe dá uma extensão mínima de $165 \mathrm{~km}$. O Falhamento de Jundiuvira foi redefinido por Hasui (1975), bem como o Falhamento de Itu, de tal modo que o limite entre os Blocos São Roque e Jundiaí é dado pelo último e parte do primeiro falhamentos.

Almeida (1953), Coutinho (1971), Sadowski (1974) e Rideg (1974) descreveram o Falhamento de Cubatão que se estende da região de Moji das Cruzes até pelo menos a região de Pedro de Toledo, totalizando uma extensão mínima de $150 \mathrm{~km}$. Coutinho (op. cit.) considerou que o Bloco Cotia se prolongaria até esse falhamento e que a sul dele apareceria o Bloco Costeiro.

Hasui (1973) descreveu o Falhamento de Caucaia que marcaria o limite meridional do Bloco Cotia e designou Juquitiba o Bloco entre esse falhamento e o de Cubatão.

No Bloco Costeiro, Rideg (1974) apontou a existência de duas zonas de falhamento importantes: a de Freires, que parece se continuar na zona de cataclase de Mongaguá, esta reconhecida por Sadowski (1974); e a de Bertioga, que havia anteriormente sido suspeitada por Ab'Saber (1962). Considerando esses falhamentos e o de Cubatão, aquele autor distingiu os Blocos Suzano, Jurubatuba, Itapanhaú e Santo Amaro, de norte para sul. O primeiro corresponde ao Juquitiba acima citado.

Os Falhamentos de Pirapora, São Roque e Jundiuvira permitem uma subcompartimentação do Bloco São Roque. Hasui (1973) chamou de Itupararanga ao Bloco isolado pelos Falhamentos de Pirapora e Taxaquara. Posteriormente, esse autor (1975) introduziu os nomes Pirapitingüi, Moreiras e Juqueri para os outros blocos. Outras descontinuidades foram reconhecidas por Almeida (1955) na região da Serra da Cantareira, mas a extensạ̃o regional delas não foi ainda estudada.

Toda essa nomenclatura, necessária em abordagens locais, se acha resumida na Fig. 2. Em termos regionais, Hasui (1975) denominou o conjunto de blocos entre os Falhamentos de Jundiuvira-Itu e Taxaquara de Conjunto São Roque (em vez de Bloco São Roque); os Blocos Cotia e Juquitiba foram incluídos no Conjunto Paranapiacaba. Esse procedimento se fundamenta em argumentos de ordem estratigráfica, que serão vistos adiante. Os blocos a sul do Falhamento de Cubatão também têm peculiaridades que os distinguem dos outros; nós os consideraremos aqui sob o nome Conjunto Costeiro (em vez de Bloco Costeiro).

A falta de estudos adequados não permite ainda precisar a extensão e o significado do estilo estrutural descrito. Braun (1972) acha que existe uma faixa rúptil estendendo-se do Estado do Rio de Janeiro até pelo menos o Rio Grande do Sul; é a sua Faixa Rúptil do Paraíba do Sul. Hasui et al. (1975) consideram que existe uma importante zona de transcorrência, a que denominaram São Paulo, passando pela faixa em foco e pelo leste paulista, que explicaria não só a diferenciação tectônica longitudinal da Faixa de Dobramentos Ribeira como também a deflexão de estruturas que, vindas do Uruguai com direção geral NNE, passam a ENE no vale do Paraíba e readquirem a direção $\mathrm{NE}$ e NNE nos Estados do Rio de Janeiro e Espírito Santo. 


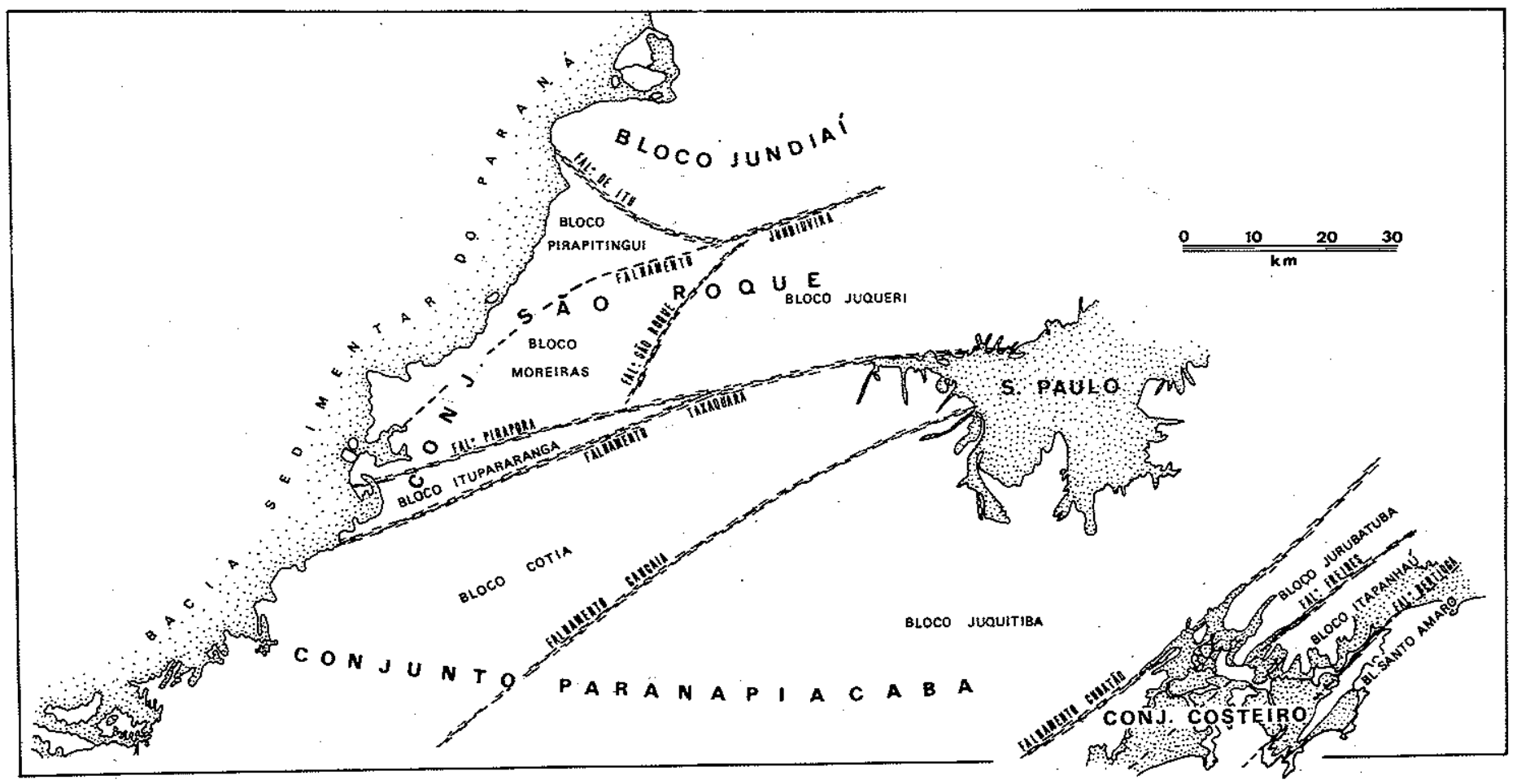

Figura 2 - Compartimentaçào tectônica 
Quanto à idade dos falhamentos, alguns tatos geológicos podem ser alinhados:

1. Os falhamentos atingiram sequiências ectiníticas geradas no Giclo Brasiliano, de modo que eles são posteriores ao metamorfismo regional.

2. Os Falhamentos de Jundiuvira (Hasui, 1975) controlou a intrusão de Sorocaba que é tarditectônica (Fig. 3).

3. No lado sul do Falhamento de Cubatão vemos alinharem-se vários stocks granitóides pós-tectônicos (Morrão, Taiaçupeba, Guaperuvu, Pai Matias e Caraú), indicañdo um controle estrutural das intrusões.

4. Fato análogo se vê com relação às intrusões granitóides na borda sul do Bloco Jundiaí, próximo aos Falhamentos de Jundiuvira e Itu. Esses corpos, segundo as dataç̃̃es disponiveis, se formaram durante o Ciclo Brasiliano e têm características de pós-tectônicos, embura encaixados em rochas pré-brasilianas.

5. Vários corpos pós-tectônicos, como os de Itu, Terra Nova e Taiaçupeba, são seccionados por fälhamentos transcorrentes. $O$ mesmo se pode dizer com relação a corpos tarditectônicos, como os de São Francisco, São Roque, Itaqui, Cantareira, Caucaia e Jarupará.

6. Não há evidências de processos de recristalização ao longo das zonas de falhamento, a não ser de quartzo (Hasui, 1975a), nem de deformações ulteriores.

Tais evidências indicam que o sistema de falhamentos se relaciona com a evoluçăo do Ciclo Brasiliano, tendo começado a se desenvolver após o metamorfismo regional e se manifestado até após o magmatismo pós-tectônico, ou seja, até a estabilização da plataforma. Esta se deu antes do Siluriano, pois o advento das condições de ortoplataforma são traduzidas pela deposição da primeira unidade estratigráfica na Bacia do Paraná. Em termos absolutos, considerando as datações disponíveis de 600 m.a. e 540 m.a. para as intrusões tardi e pós-tectônicas (Cordani e Kawashita, 1971), temos aí o intervalo mínimo durante o qual o sistema de falhamentos se desenvolveu. Dentre as datações K-Ar de metamorfitos relatadas por Cordani e Bittencourt (1967) e Hasui e Hama (1972), as cifras mais elevadas chegam a 650 m.a. Apenas um metabasito do Grupo São Roque forneceu cifra de 710 m.a., que consideramos ser um valor mínimo para a formação da rocha básica (magmatismo pré-tectônico do Ciclo Brasiliano) e para o metamorfismo regional. Assim, o limite inferior de idade para o sistema de falhamentos se situa além de $710 \mathrm{~m}$.a. Com relação ao limite superior, lembramos que o vulcanismo ácido-intermediário associado às molassas do Ciclo Brasiliano tem idade em torno de $450 \mathrm{~m}$.a. Aquém desta idade é que se deu a passagem de condições paraplataformais para ortoplataformais e, certamente, a atenuação dos movimentos lineagênicos.

Evidentemente, a evolução dos falhamentos não foi contínua mas episódica, através de alívios de tensões de tempos em tempos. A movimentação mais intensa se deu após o magmatismo pós-tectônico.

A configuração atual dos blocos não se deve só aos movimentos durante o Ciclo Brasiliano.

Num exame dos sedimentos do Grupo Tubarão, Hasui (1973) mostrou que eles estão fraturados mais densamente ali onde recobrem o Falhamento de Taxaquara do que alhures. Ademais, as fraturas formam sistemas que coincidem com as do embasamento, o que foi interpretado como indício de reativação das descontinuidades do Precambriano.

Sadowski (1974) lembra o já conhecido magmatismo básico na zona costeira sob forma de diques e sills (Ilha Porchat, Engenheiro Ferraz, Serra do Quilombo, tha de Santo Amaro, Zanzalá etc.), relacionado com a Reativação Wealdeniana da Plataforma Sul-Americana (Almeida, 1967) e traduzindo regimes tracionais de tensão. Falhas de 


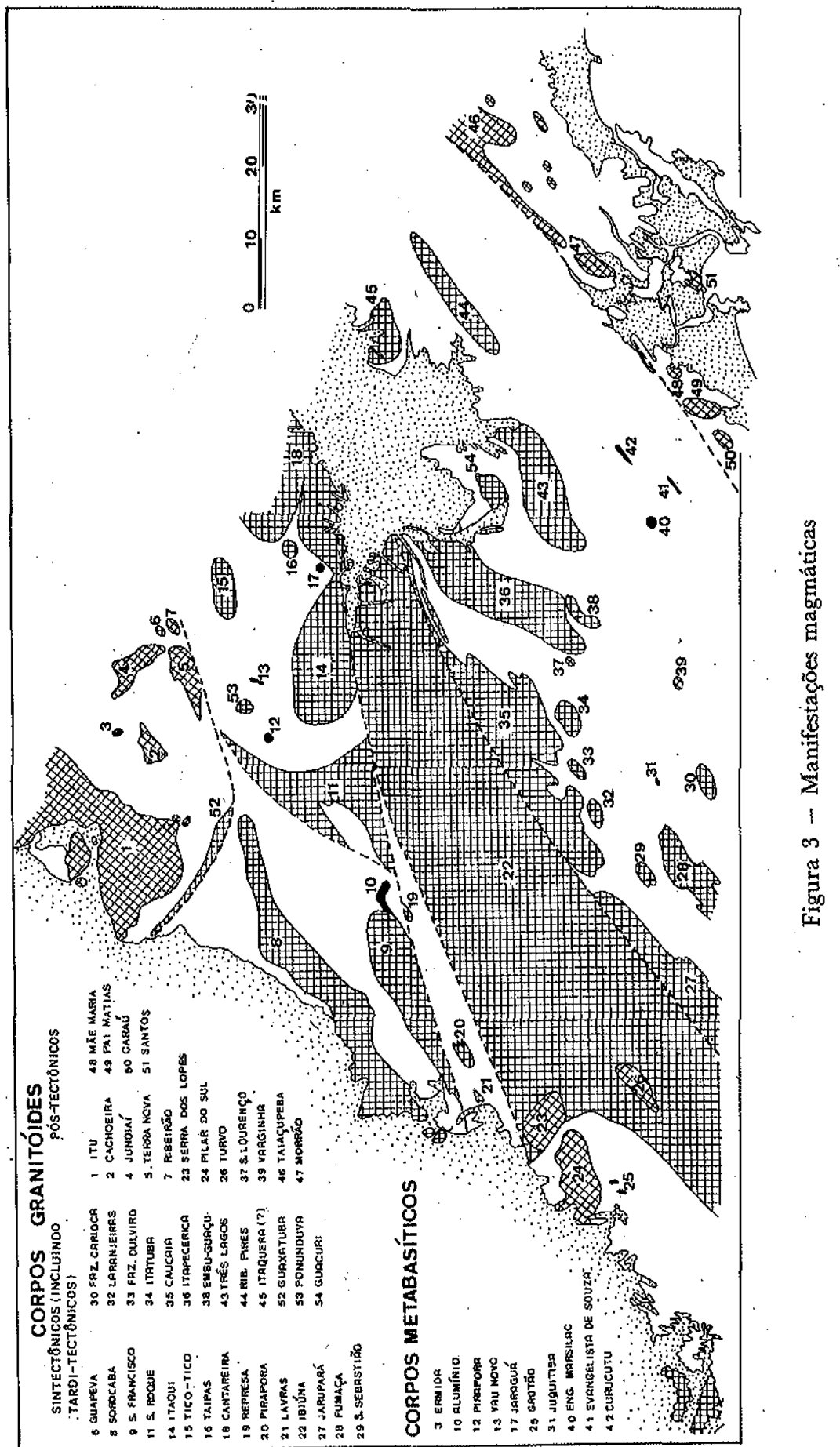


gravidade de pequeno porte têm sido assinaladas (Vandoros e Oliveira, 1969; Sadowski, 1974) e é a um regime tracional, criando falhas normais paralelas à costa, que muitos autores têm atribuído a configuração geomorfológica da zona litorânea em três níveis escalonados (a baixada, os marrotes a 200-300 $\mathrm{m}$ de altitude, a zona do Planalto Paulistano nivelado a cerca de $800 \mathrm{~m}$ de altitude). Por fim, falhas em sedimentos considerados terciários têm sido assinaladas, como por Rideg (1974).

Tais fatos e evidências apontam uma evolução fanerozbica dos blocos ainda mal compreendida, mas que certamente modificou a configuração imposta pelo Ciclo Brasiliano.

LITOLOGIA O Conjunto São Roque é constituído por ectinitos representados por filitos sericíticos e grafitosos em meio aos quais aparecem quartzitos, micaxistos, metabasitos, anfibolitos, calcários, dolomitos, rochas calcossilicatadas (Cordani et al., 1963) e raros metaconglomerados (Coutinho, 1955; Hasui et al., 1969; Ellert, 1964). No Conjunto Paranapiacabạ, litologia análoga aparece na parte SW (região de Pilar do Sul) e migmatitos dominam na região a $\mathrm{S}$ e SE da capital paulista. Já no Bloco Cotia os migmatitos estão presentes, como no anticlinório desventrado de Ibiúna (Hasui, 1975a) e na região de São Paulo (Franco, 1956).

O Bloco Juquitiba e os Conjuntos Costeiro e Jundiaí são constituídos em essência por mignatitos (Mehnert, 1968) que envolvem generalizadamente um paleossoma xistoso ou gnáissico e neossoma granitóide ou pegmatóide. No paleossoma xistoso observa-se' a incidência de quartzo e mica (biotita e/ou clorita e/ou moscovita); no gnáissico, aparecem adicionalmente feldspatos. Os acessórios mais significativos são granada (almandina) e sillimanita. Migmatitos estromatíticos predominam nos Blocos Jundiá e Juquitiba, eles estão presentes também no Costeiro, mas tanto aqui, como na parte SE do Juquitiba, tem-se o domínio de migmatitos oftalmíticos. Na zona litorânea, Sadowski (1974) descreveu anatexitos e diatexitos. Outros tipos de migmatitos ocorrem em todos os blocos, mas subordinadamente.

Em meio aos migmatitos encontramos anfibolitos, rochas calcossilicatadas e quartzitos, praticamente não afetados pela feldspatização.

No Bloco Juquitiba existem algumas faixas ectiniticas embutidas em estruturas sinformais. No Sinclinório de Cipó (Hasui et al., inédito) aparecem micaxistos finos sobrepostos por quartzo-xistos. No Sinclinório de Cubatão (Sadowski, 1974) aparecem, da base para o topo, quartzitos conglomeráticos, quartzitos com intercalações anfiboliticas, biotita-xisto granatífero, micaxisto fino com intercalações de quartzito, de dolomito e de metamarga. Oito intercalaçбes carbonáticas foram observadas no túnel da Usina Henry Borden, com espessuras individuais de 1 a $65 \mathrm{~m}$. Os quartzitos basais parecem aumentar de espessura para leste, chegando a $1500 \mathrm{~m}$ (Vandoros e Oliveira, 1969).

No Conjunto Costeiro, Sadowski (1974) distinguiu uma faixa ectinítica na Serra do Morrão, portando xistosidade $\mathrm{N} 40 \mathrm{E}$ inclinada para SE, sobre migmatitos com foliação N80W. A relação de contato parece ser de discordância angular ao menos na zona próxima ao Rio Quilombo; de resto, a relação não pôde ser verificada ainda. Seja como for, a hipótese de falhamento não pode ser excluída de momento.

Um corpo de granulito foi descrito por Rideg (1974) em Bertioga em meio aos migmatitos do Bloco Santo Amaro.

Todos os conjuntos apresentam corpos granitoides petrograficamente heterogêneos e homogêneos. Os primeiros possuem porfiroblastos de microclíneo e plagioclásio desenvolvidos por metassomatose tardia, em matriz de natureza granodioritica a quartzo-diorítica; essa metassomatose incidiu com intensidades variadas, resultando composições 
finais que variam de granítica a granodiorítica. As rochas exibem texturas inequigranular seriada, porfiroblástica e microporfiroblástica; onde os feldspatos mostram bom desenvolvimento, tem-se vulgarmente utilizado os nomes "granito Pirituba, olho-de-sapo ou Varejão". Os porfiroblastos no seu crescimento promoveram desvios da foliação da matriz; esta tende a se desfazer com o aumento de tamanho e quantidade deles, eventualmente chegando-se a ter texturas isotrópicas. Só localmente, talvez por influência da anisotropia da matriz, os feldspatos se apresentam orientados planarmente. Os feldspatos presentes são oligoclásio e microclíneo; o acessório universal é a biotita, em geral parcialmente cloritizada. Xenolitos e corpos de metassedimentos (tetos pendentes) são encontradiços. Descrições mais detalhadas foram apresentadas por Ellert (1964), Coutinho (1953, 1972), Hasui (1973) e, fora da faixa em pauta, por Wernick (1972).

Os corpos homogêneos são graníticos ou adamelíticos, não portando as rochas qual. quer orientação de minerais ou indícios de cataclase intensa que não os atribuíveis aos falhamentos transcorrentes (ao contrário dos granitóides acima, onde os fenômenos de cominuição são generalizados).

Em todos os blocos aparecem sedimentos cobrindo as unidades anteriores. As camadas mais antigas pertencem ao Grupo Tubarão, que aparece na parte NW da área focalizada; é representado por sedimentos arenosos, conglomeráticos e argilosos de origem glacial, flúvio-glacial e lacustrino-glacial.

Os demais depósitos são cenozóicos, compreendendo:

1. os sedimentos tidos como terciários da Bacia de São Paulo, representados por argilas e intercalaçöes arenosas e conglomeráticas. Na superfície são variegados, freqüentemente com crostas limoníticas associadas. São de origem fluvial. Um estudo detalhado foi apresentado por Leinz e Carvalho (1957);

2. os sedimentos que por sua semelhança litológica têm sido correlacionados com os da Bacia de São Paulo, mas estão ligados à evolução da rede de drenagem atual; situam-se em encostas e acham-se em vias de erosão;

3. os sedimentos lacustrinos da Depressão de Colônia. A depressão tem $2,5 \mathrm{~km}$ de diâmetro e origem provável por impacto meteorítico; os sedimentos somam espes suras de $285 \mathrm{~m}$ (Kollert et al., 1961);

4. os sedimentos costeiros, representados pelas areias de praia, dunas, cordões litorâneos ou restingas;

5. os sedimentos das partes interiores das baixadas litorâneas, onde aparecem os manguezais. Aí ocorrem camadas arenosas, argilosas e turfáceas, próprias de ambiente paludial e lagunar;

6. os sedimentos recentes ligados à rede de drenagem atual, essencialmente areno-argilosos;

7. os depósitos de encosta e de piemonte, representados por materiais rudáceos de cones de dejeção, tálus e coluvios.

Corpos de rochas básicas mesozóicas se introduziram esparsamente, sobretudo na zona litorânea, como anteriormente citado. Além deles, resta lembrar os corpos de rochas alcalinas, também mesozóicos, que aparecem no vale do Rio Sarapuí (Felicissimo Jr., 1968) e em Araçoiaba da Serra (Davino, 1970).

ESTRATIGRAFIA Em que pese a compartimentação tectônica que descrevemos, atribuímos significado, em termos de unidades estratigráficas, aos Falhamentos de Jundiuvira-Itu, Taxaquara e Cubatão, isolando os Conjuntos Jundiaí, São Roque, Paranapiacaba e Costeiro. 
O Grupo São Roque limita a sua distribuição ao Conjunto São Roque. Ė uma unidade ectinítica vinculada ao Giclo Brasiliano com base em datações geocronológicas.

O Grupo Açungui tem domínio no Conjunto Paranapiacaba. Essa unidade foi no passado considerada como simples prolongamento do Grupo São Roque e, mais, como sendo de natureza ectinítica.

Hasui (1973) verificou a existência de diferenças estruturais significativas entre as duas unidades, traduzindo diferentes condições tectônicas que poderiam ser compreendidas se considerássemos os grupos São Roque e Açungui como constituídos em bacias geossinclinais distintas ou em diferentes zonas de uma mesma bacia. Hasui et al. (1975) mostraram que a hipótese de bacias distintas é viável dentro do padrão de organização transversal do Sistema Ribeira. Seja como for, existe semelhança litologica, geocronológica, magmática e mesmo metamórfica entre os Grupos Açungui e São Roque, da mesma forma que há entre esses grupos e os Grupos Brusque-PorongosuLavalleja e Rocha, sem que possamos considerar todas essas unidades como prolongamentos entre si.

O posicionamento face a face dos Grupos São Roque e Açungui se deve ao Falhamento de Taxaquara, cujo rejeito é superior à sua extensão conhecida $(165 \mathrm{~km})$, conforme ponderações de Hennies et al. (1967a).

Os migmatitos têm sido tradicionalmente considerados à parte como compondo um Complexo Cristalino ou Migmatítico, que muitos consideram mais antigo. Hasui (1975a) e Sadowski (1974) mostraram que, excluindo o fenômeno de migmatização e o grau de metamorfismo, nenhuma diferença existe entre essas rochas e as incluidas no Grupo Açungui, e concluem que os migmatitos do Conjunto Paranapiacaba podem ser incluídos nessa unidade estratigráfica.

Essa conclusão vai de encontro às observações de Melfi et al. (1965) e de Melcher et al. (1973), segundo as quais na região de Barra do Turvo no Vale do Ribeira há passagem gradual de filitos para migmatitos. Nos mapas geológicos dessa região (Bettencourt et al. 1971; Cordani et al., 1971; Cordani et al., 1971a), embora sem individualização, os migmatitos são considerados como pertencentes ao Grupo Açungui e em parte como integrantes de um complexo pré-brasiliano. Poder-se-ia presumir que as zonas migmatizadas, correspondendo a níveis mais profundos da faixa dobrada, comporiam uma unidade pré-Açungui, reservando-se o nome Açungui para a parte ectinítica. Este procedimento, contudo, implica atribuir ao front de migmatização um significado estratigráfico, o que certamente não é correto. Levando em conta a importância de se separar litologias tão dispares, Hasui (1975a) distinguiu em termos puramente litológicos o Complexo Pilar, incluindo os ectinitos presentes na regiạ̃o de Pilar do Sul e que continuam no Vale do Ribeira, e o Complexo Embu, compreendendo os migmatitos existentes a sudeste daqueles ectinitos e que podem ser mais bem vistos na região de Embu-Juquitiba.

O Complexo Pilar comparece na faixa abordada na parte sudoeste do Bloco Cotia; o Complexo Embu está presente também nesse bloco, mas seu domínio é no Bloco Juquitiba. Caminhando de NW para SE, passa-se de ectinitos de fácies xisto verde para migmatitos estromatíticos e, por fim, ao nos aproximarmos do Falhamento de Cubatão, dá-se o aparecimento de migmatitos oftalmíticos. Na passagem ectinitos-migmatitos interpôs-se o Batólito de Ibiana, mas de qualquer modo no sentido indicado há aumento do grau de metamorfismo e do grau de migmatização.

$\mathrm{Na}$ área do Complexo Embu algumas estruturas sinformais foram identificadas, observando-se aí decréscimo da migmatização para o núcleo, chegando a se ter rochas ectiníticas. As passagens são transicionais. E o caso do Sinclinório de Cípó e possivelmente também do Sinclinal de Itaqüera, onde Coutinho (1972) reconheceu a existência de micaxistos muito finos. Reciprocamente, em estruturas anticlinoriais nota-se a intersi- 
ficação da migmatização para o núcleo, como no anticlinal de São Lourenço, e, próximo ao Falhamento de Cubatão, nas partes cuntrais chegam a se expor rochas que exibem deformações e migmatizações mais complicadas que no Complexo Embu, e que consideramos como tratos do embasamento pré-brasiliano. Sadowski (1974) delimitou quatro de tais zonas na parte SE do Bloco Juquitiba, que aqui denominaremos Núcleos Zanzalá, Capivari, Evangelista de Souza e Pilões, como é indicado na Fig. 4.

O Conjunto Costeiro $e$ formado por migmatitos de três tipos fundamentais: 1) os estromatíticos, com neossoma calco-alcalino, 2) os porfiroblásticos, em que os porfiroblastos são de microclíneo róseo e 3) os anexíticos e diatexíticos, restritos à zona beira-mar. Os primeiros sofreram feldspatização alcalina de modo a gerar o tipo 2; na região $\mathrm{SE}$ até fusão parcial ocorreu para se constituir o tipo 3. Estes fenômenos, embora regionais, não atingiram uniformemente a área; assim é que encontramos zonas praticamente não afetadas lembrando enclaves quase intatos como nas regiões das Serras de Jurubatuba e do Quilombo e da Rodovia Pedro Taques, nas proximidades do cruzamento com a Rodovia dos Imigrantes.

Outros dados serão expostos adiante, mas lembramos que o Conjunto Costeiro é constituído de uma seqüência particular que admitimos ser pré-brasiliana. Denominamo-la aqui Complexo Piaģagüera.

Na Serra do Morrão, como mencionamos antes, existe um pacote de rochas ectiníticas aparentemente em discordância sobre os migmatitos. Esses ectinitos em tudo se assemelham aos que existem no Sinclinório de Cubatão e não há razão para não os incluir bem como os ectinitos do Sinclinório de Cipó, no Complexo Pilar.

No tocante à subdivisão das unidades estratigráficas ou litológicas apresentadas, defrontamo-nos com um problema de dificil solução. O Complexo Pilar e o Grupo São Roque oferecem melhores possibilidades; todavia, tratando-se de seqüencias essencialmente metapelíticas, em que litologias mais favoráveis constituem simples intercalações lenticulares, não se dispõe de horizonte-guia. Podem-se reconhecer seqüências locais. No Sinclinório de Pirapora (Fig. 4), pode-se reconhecer um nivel configurado pelas lentes de rochas calcárias em meio a metapelitos; abaixo dele encontram-se metapelitos com lentes de quartzito tão possantes como as que sustentam o Pico do Jaraguá (Cordani et al., 1961) e a Serra de Boturuna (Hasui et al., 1969) bem como metaconglomerados; acima dele aparecem filitos rítmicos (Hasui, 1973). Pode-se pensar em três unidades, mas seus limites no terreno são dificeis de ser fixados. No Sinclinório de Cubatão, temos a seqüuencia calcária se sobrepondo a outra essencialmente pelítica com metapsamitos associados (Sadowski, 1974).

Finalmente, o Conjunto Jundiaí é constituído de migmatitos e resisters notáveis, como os quartzitos da Serra do Japi; essa litologia englobamos sob o nome Complexo Jundiai. Em termos geocronológicos, uma datação K-Ar no anfibolito de Ermida forneceu resultado de 1100 m.a. (Hasui e Hama, 1972), o que indica idade pré-brasiliana do bloco. Os granitos nele intrusivos, com características de pós-tectônicos, foram datados por $\mathrm{Rb}-\mathrm{Sr}$, obtendo-se idade de 540 m.a. (Cordani e Kawashita, 1971). Dentre essas intrusões merecem ser lembradas as de Itu e de Jundiaí.

MAGMATISMO $O$ magmatismo que se reconhece na faixa focalizada se deu em fases distintas. Para os Conjuntos São Roque e Paranapiacaba podem ser feitas várias considerações.

Os corpos metabasíticos (Fig. 3), nos quais ainda se reconhecem vestígios da mineralogia e textura originais, traduzem uma primeira fase. Os corpos de Alumínio e Pirapora, entre outros, se constituíram no Conjunto São Roque; no Conjunto Paranapiacaba, 


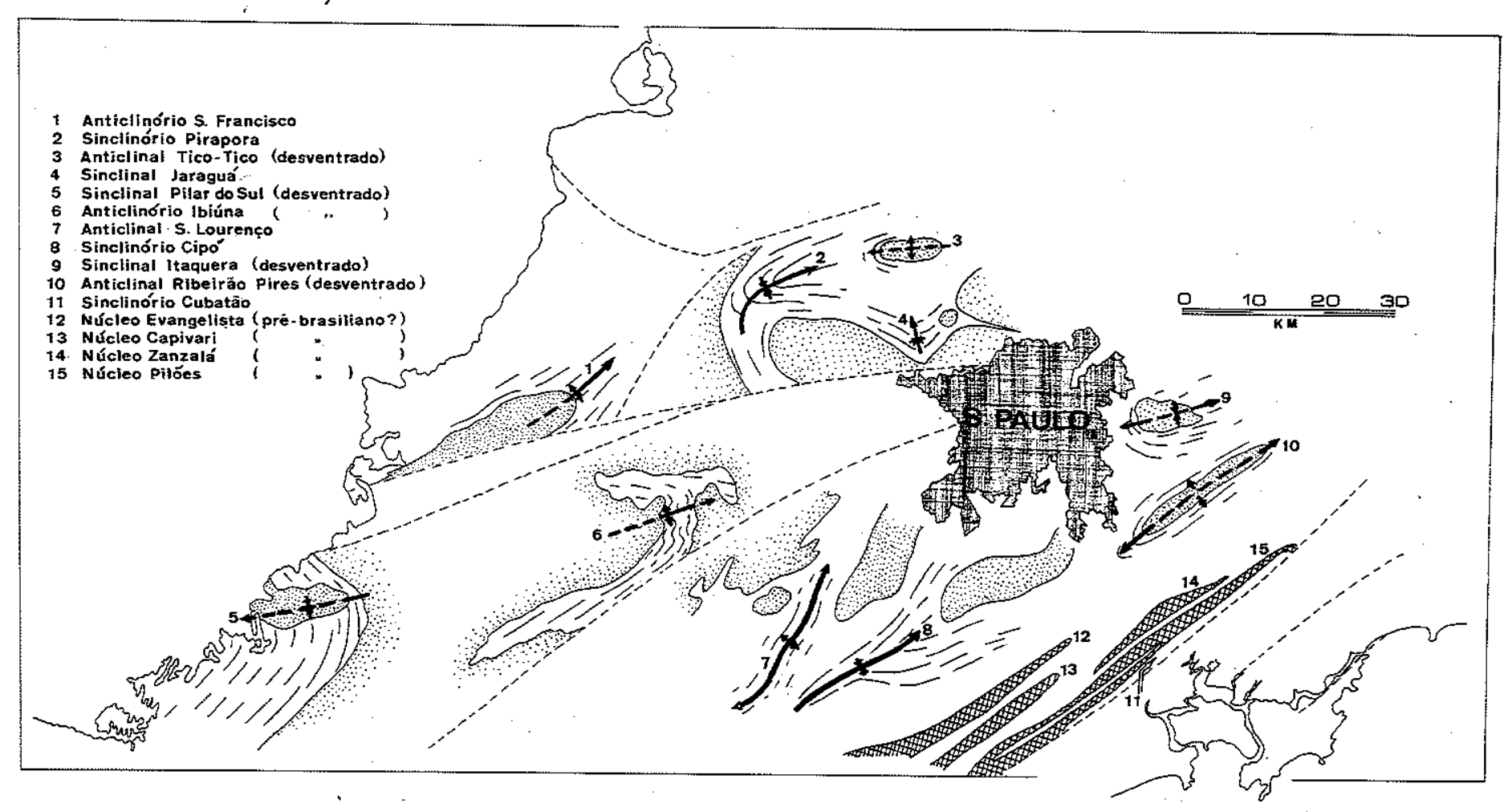

Figura 4 - Principais macroestruturas 
exemplos nos são dados pelas ocorrências de Grotão, Juquitiba, Evangelista de Souza e Engenheiro Marsillac. As transformações sofridas pelas rochas são devidas ao metamorfismo regional, o que indica precedência do magmatismo básico em relação àquele fenômeno, isto é, trata-se de um magmatismo pré-tectônico.

Os corpos granitóides heterogêneos se constituíram numa segunda fase. Hasui (1975a) mostrou que no Conjunto São Roque esses corpos se formaram logo após o metamorfismo regional e ainda sob vigência de um regime de tensão, devendo ser qualificados como tarditectônicos; já no Complexo Paranapiacaba, corpos semelhantes se formaram sob regime de tensão, mas sem vinculação com o metamorfismo regional, devendo ser qualificados sintectônicos. Nós englobaremos todos eles sob a qualificação sintectônicos, conferindo a este termo significado amplo que inclui os tarditectônicos.

Tais corpos são alongados, com maior eixo paralelo ao alinhamento das estruturas regionais. Seus contatos /são mormente concordantes, ao menos em direção, mas em pequenos segmentos há nítida discordância. Eles são perfeitamente delimitáveis, pois o contato é sempre nítido. No Conjunto São Roque eles se alojaram em núcleos de antiformas, que são definidas pelas faixas mais ou menos largas de rochas de maior grau metamórfico à sua volta, como se vê nos maciços de São Francisco, Tico-Tico (Penalva e Hasui, 1970), Itaqui, Cantareira e São Roque (pro-parte). Esses corpos introduzindo-se sob vigência de condições dinâmicas foram capazes de influir no modelado das estruturas das encaixantes, tanto que estas parecem se amoldar aos corpos. No Conjunto Paranapiacaba, estruturas dômicas não são tão evidentes, a não ser em volta do corpo de Três Lagos que se introduziu no núcleo do Anticlinório de Cipó. O modelado das estruturas; contudo, foi influenciado, como se pode verificar pelos desvios de orientação, por exemplo, na região de Embu.

Os corpos sintectônicos impuseram modificações de contato às encaixantes. Franco (1958), Coutinho (1953) e Hasui (1973) descreveram hornfels calcossilicáticos, básicos e aluminosos, e Gomes (1971) estudou detidamente os anfibolitos de Jaraguá, mostrando a ação periférica dessas intrusões. Além disso, os metamorfitos sofreram turmalinização e se acham injetados de pegmatitos, como se vê na região de Perus ou de Mairiporã. Também nas regiões migmatíticas a ação pneumatolítica é observada. Piritização e apatitização incipientes são freqüentemente observadas.

A rocha granitóide foi descrità anteriormente e o aspecto preeminente é a presença da foliação que concorda com as direções estruturais regionais.

Alguns desses corpos foram analisados por Cordani e Kawashita (1971), que obtiveram idade de 600 m.a. ( $\mathrm{Rb} / \mathrm{Sr}$ ) e razão inicial indicativa de remobilização de material siálico. Esse material gerado em maior profundidade ascendeu na coluna de rochas até níveis mesozonais, sendo então parautóctonos.

Corpos granitóides pós-tectônicos se formaram numa terceira fase. São os corpos homogêneos já mencionados. Via de regra, eles são de menor porte e alguns foram datados por Vandoros e Franco (1966) e por Cordani e Kawashita (1971), com idade de 540 m.a.

A história magmática dos Conjuntos São Roque e Paranapiacaba pode ser considerada em conexão com a evolução da Faixa de Dobramentos Ribeira, em termos de eventos pré-, sin- e pós-tectônico. $O$ magmatismo sintectônico foi o mais importante. Nenhuma das fases mostra controle geral de distribuição espacial, a não ser os casos anteriormente citados relacionados com falhamentos transcorrentes.

As demais manifestações magmáticas reconhecidas são juro-cretáceas e vinculadas à Reativação Wealdeniana.

No Bloco Jundiaí e no Conjunto Litorâneo, os corpos granitóides existentes são similares aos pós-tectônicos descritos, parecendo vincular-se ao Giclo Brasiliano. 
METAMORFISMO No Grupo São Roque e no Complexo Pilar, o metamorfismo regional se deu em fácies xisto verde a anfibolito; litologias de fácies anfibolito são reconhecidas nas periferias de corpos granitóides sintectônicos.

Nos Complexos Embu e Piaçagüera, o metamorfismo se deu em fácies anfibolito. A única notícia de rochas granulíticas foi dada por Rideg (1974) em Bertioga, com a associação hornblenda-ortopiroxênio-plagioclásio.

Para os Complexos Embu e Pilar podem-se reconhecer zonas de clorita, biotita, almandina e sillimanita, genericamente distribuídas em faixas sucessivas à medida que se dirigem de NW para SE. $\mathrm{O}$ zoneamento não é geometricamente simples, mas as faixas têm formas algo irregulares, como mostrou Coutinho (1972), para a região da capital paulista. A incidência de cianita sob forma de detritos em sedimentos aluvionares e solos fói verificada por Suguio (1971), mas a distribuição desse mineral no Precambriano não foi ainda determinada. Em termos de séries metamórficas, esse conjunto de dados condiz com a Série Barroviana, como reconheceu Rideg (1974).

Em ligação com as intrusões sintectônicas e pós-tectônicas, os metamorfitos sofreram transformaçð̃es de contato, já mencionadas.

Um fato ainda mal compreendido é o desenvolvimento de porfiroblastos e microporfiroblastos de moscovita em metapelitos. Coutinho (1972) atribuiu-os a uma metassomatose potássica tardia. Hasui (1973) nota que os porfiroblastos se distribuem caoticamente, o que traduziria cristalização em condições estáticas, anterior ao processo de transposição que promoveu rotações dos cristais. Rideg (1974) acha que eles se cristalizaram em zonas de menor pressão de microdobras e conclui que sua formação é sincrônica ao dobramento.

Nas rochas de fácies anfibolito se observa generalizạdamente a incidência de associações mineralógicas em desequilíbrio, como biotita/clorita, plagioclásio com borda albítica ou saussuritizado, zoisita/clinozoisita, granada/clorita e sillimanita/moscovita. Tais associaçð̄es indicam um processo de retrometamorfismo em condições fisicas já bem atenuadas. Hasui (1975) considera que talvez esse processo tenha ocorrido em conjunção com o reaquecimento introduzido pelo magmatismo pós-tectônico.

Por firn, cabe menção aos efeitos cataclásticos das zonas de falhamento. Eles são flagrantes em rochas granitóides, como descreveu Hasui (1975a). O processo de fragmentação e cominuição não foi uniforme na zona de falhamento, havendo faixas onde foi mais intenso alternando-se com outras onde a intensidade foi menor; tais faixas têm espessuras deci- a decamétricas e chegam a somar centenas de metros e até mais de $1 \mathrm{~km}$. Petrograficamente, reconhecemos brechas, protomilonitos, milonitos, filonitos e ultramilonitos. Somente o quartzo chegou seguramente a se recristalizar.

No Conjunto Litorâneo prevaleceram condições de fácies anfibolito e granulito. Tanto aí, como no Bloco Jundiaí, os estudos realizados não permitem ainda consideraçóes em termos de evolução metamórfica.

MIGMATIZAÇÃO A migmatização é um fenômeno que afetou o Complexo Embu com intensidade de modo geral crescente de NW para SE e também rumo ao núcleo de estruturas culminantes, como já dissemos. A estrutura dos migmatitos é simples, indicando que o processo foi unifásico e ocorreu durante ou logo após o metamorfismo regional, dependendo o posicionamento temporal do modelo genético que se admitir para origem do neossoma. O neossoma é essencialmente alcalino, com microclíneo como feldspato onipresente; a incidência de plagioclásio (oligoclásio) é normalmente restrita.

No Complexo Piaçagüera, os migmatitos não são simples. E dificil identificar fases e regionalizá-las, mas algumas considerações a respeito já são possíveis graças aos estudos 
de Sadowski (1974). Numa primeira fase, o neossoma desenvolveu-se em concordância com a xistosidade, configurando estrutura estromatítica; o neossoma é calco-alcalino, o feldspato sendo plagioclásio (oligoclásio). Em outras fases de migmatização constituíram-se neossomas discordantes, de natureza alcalina. Esses neossomas são de dois tipos quanto à estrutura íntima: os foliados e os não-foliados. Os foliados têm micas orientadas, aparentemente em concordância com os planos axiais de dobras configuradas pelo paleossoma e neossoma estromatíticos; eles devem ter-se constituído durante uma fase dinâmica. Os não-foliados têm as micas dispostas caoticamente e devem ter-se desenvolvido em fase estática. Freqüentemente, vemos esses neossomas em forma de veios que se entrecruzam, sugerindo que sua constituição se deu em várias fases ou foi prolongada.

Além desses processos de migmatização, houve também oftalmogênese alcalina. Os feldspatos não estão orientados, a não ser localmente, e aí a orientação pode ser explicada por controle exercido por/anisotropia pré-existente na rocha. A blastese se deu em condições estáticas. Sadowski (1974) interpretou o fenômeno como incidindo em profundidade maior, enquanto aqueles neossomas discordantes acima descritos se constituiriam em níveis menos profundos. Desse modo, se os migmatitos oftalmíticos se achassem expostos, no atual nível de erosão, ao lado de migmatitos com neossomas individualizados, seria de se inferir que um processo de deformação afetou o conjunto, permitindo pensar-se em termos de antiformas e sinformas com núcleos respectivamente oftalmíticos e venulados.

$E^{\hbar}$ verdade que, em virtude de transições de tipos de migmatitos, não é fácil estabelecer-se a distribuição espacial; todavia, em termos regionais, a existência de faixas alongadas mais ou menos paralelas não é de se estranhar, como as indicadas por Sadowski (op. cit.).

Em suma, a migmatização no Complexo Piaçagüera foi polifásica, assim diferindo notavelmente do Complexo Embu. Se confirmáda a idade pré-brasiliana daquele, a evolução migmatítica além de polifásica foi provavelmente policíclica.

No Bloco Jundiaí, os dados disponíveis não permitem considerações sobre a evoluçã̃o migmatítica.

DEFORMAÇÃO No Grupo São Roque, as dobras visíveis em afloramentos e amostras são similares, cerradas (eventualmente fechadas e isoclinais), com planos axiais subverticais. A xistosidade é plano-axial, mostrando que o metamorfismo regional se deu contemporaneamente ao dobramento. Os eixos dessas dobras são sub-horizontais e dirigidos em geral segundo N60E. Desvios de orientação existem, como na região de Araçariguama e Jaraguá, explicáveis por acomodação aos contornos dos corpos granitóides sintectônicoș.

Nos Complexos Embu e Pilar, as dobras visíveis nos afloramentos e nas amostras são também similares, cerradas (ocasionalmente fechadas e isoclinais), com planos axiais subverticais. Os eixos são igualmente sub-horizontais e se orientam segundo N45E no geral dentro da região aqui focalizada. Desvios direcionais locais existem, como na região de Embu, onde as atitudes chegam a N30E, mas explicáveis por influência das intrusões granitóides sintectônicas próximas.

O estilo geral das dobras se assemelha no Grupo São Roque e nos Complexos Embu e Pilar, o que pode ser atribuído a uma fase de deformação em comum. Uma peculiaridade existe, porém, nos Complexos Embu e Pilar: a xistosidade não é plano-axial mas sim paralela à estratificação reliquiar, pelo menos dentro da região em pauta. Este fato constitui uma indicação de redobramento, que pelos dados disponíveis implicaria uma primeira fase de dobramento isoclinal ou cerrado recumbente, com xistosidade plano-axial, e uma segunda fase coaxial gerando aquelas dobras visíveis nos afloramentos (Hasui, 1975a). Para comprovar essa indicação resta ainda executar investigações de detalhe. 
No Complexo Piaçagüera, os migmatitos estromatíticos exibem dobras visíveis nos afloramentos e nas amostras que ondularam a xistosidade do paleossoma e o bandamento estromatítico. As dobras são também similares, cerradas (por vezes isoclinal e fechada); as particularidades que exibem dizem respeito à atitude. Seus eixos se orientam segundo N40E no geral e os planos axiais mergulham de baixo ângulo para SE, existindo uma forte recumbência indicando polaridade estrutural para NW (vergência).

Tais são as deformaçốes do estado plástico. As demais advieram quando as rochas ganharam rigidez suficiente para se romper, provavelmente com a atenuação das condiçôes físicas após a inversão do geossinclíneo.

Generalizadamente, houve de início desenvolvimento de um processo de crenulação e transposição. Estudos pormenorizados se fazem ainda necessários para compreender a variação espacial desse fenômeno. Ora ele se traduz por deformações de cisalhamento simples, ondulando estruturas planares pré-existentes e complicando as dobras anteriormente formadas. Quando se manifestam planos de cisalhamento, estes induzem deformações nos microlitons, podendo-se falar numa clivagem de fratura ou em strain-slip cleavage. Intensificando os movimentos, as estruturas presentes nos microlitons são levadas a se paralelizar com as descontinuidades; assim é que a xistosidade tende a se transpor para nova posição, aparecendo estruturas filoníticas.

No Complexo Piaçagüera, houve pronunciado processo de transposição que em. parte antecedeu a migmatização alcalina e talvez date de tempos pré-brasilianos.

Outra fase de deformação se manifestou através dos falhamentos transcorrentes, todos subverticais. Estes configuram um sistema apenas parcialmente conhecido, mas que parece ser atribuível a um regime de esforços E-W (Hennies et al., 1967; Hasui, 1975a). Nas zonas de falhamento reconhecem-se lineaçôes de atrito indicando além da componente horizontal do rejeito, também uma pequena componente vertical, com elevação dos blocos que se deslocaram para o oriente (Hasui, 1975a). Essa deformação se deu, como vimos, entre fins do Precambriano e o Siluriano.

Uma falha de empurrão foi identificada no Conjunto Costeiro, próximo ao Falhamento de Cubatão. Ela mergulha de 20 a $30^{\circ}$ no rumo SE. Os estudos na região são extremamente dificultados pela falta de acesso e pela densa cobertura vegetal, mas é de se presumir que outras falhas semelhantes venham a ser descobertas.

Por fim, embora năo datadas, cumpre lembrar os sistemas de juntas e falhas menores. Os estudos de Hasui (1973) e Sadowski (1974) indicam que existem um sistema subvertical transversal à xistosidade; dois sistemas conjugados oblíquos a cerca de $50^{\circ}$ da xistosidade, com indícios de cisalhamento; um ou dois sistemas sub-horizontais (menos de $40^{\circ}$ ). Um destes últimos sistemas freqüentemente é subparalelo à superficie do terreno e chega a lembrar juntas de alívio de carga; todavia, quando os dois sistemas são vistos, eles são conjugados.

Os sistemas subverticais de juntas, a xistosidade e a estratificação reliquiar exerceram forte controle na drenagem dentro do relevo maturo que caracteriza a maior parte da área (Hasui, 1975a).

Os falhamentos e as demais descontinuidades parecem ter sofrido reativações em épocas posteriores, como mencionamos antes.

Como se vê, a deformação na área considerada se deu em várias fases, a maior parte delas em vinculação com o Ciclo Brasiliano. Excluímos das considerações o Bloco Jundiaí, onde estudos ainda devem ser realizados.

EVOLUÇÃO GEOLÓGICA Os eventos de deformação e de cristalização descritos anteriormente podem ser correlacionados com base em critérios estruturais micro-, meso- 
e macroscópicos (Hasui 1975), de modo a se estabelecer a história geológica precambriana pelo menos dos Conjuntos São Roque e Paranapiacaba.

No Conjunto São Roque, o magmatismo pré-tectônico antecedeu o metamorfismo regional. Este se deu em fácies xisto verde a anfibolito; a xistosidade que se desenvolveu é do tipo plano-axial, atestando que se desenvolveu em conjunção com os dobramentos visíveis em amostras e afloramentos. Ainda sob o regime dinâmico responsável pelos dobramentos, mas após o metamorfismo regional, deram-se as intrusões sintectônicas (tarditectônicas, stricto sensu), que impuseram metamorfismo local de contato. Essas intrusões granitóides se alojaram em núcleos de estruturas culminantes e em parte contribuíram para o modelado dos dobramentos.

Posteriormente, já em condições fisicas atenuadas, sobreveio o processo de crenulação e. transposição. As rochas sofreram em seguida metamorfismo retrógrado.

No Conjunto Paranapiacaba, também o magmatismo pré-tectônico antecedeu o metamorfismo regional. Este fenômeno se deu em fácies xisto verde a anfibolito e a xistosidade desenvolvida foi de tipo plano-axial em relação a presumidas dobras isoclinais ou cerradas recumbentes. A migmatização ocorreu durante ou logo após o metamorfismo regional. Posteriormente, sobreveio o dobramento que gerou as ondulaç̃̃es visiveis em afloramentos e amostras. Estas dobras superimpuseram-se ao que parece coaxialmente às anteriores e durante seu desenvolvimento deram-se as intrusões granitóides sintectônicas, impondo metamorfismo de contato às encaixantes. Com o advento de condiçø̃es fisicas menos intensas, sobreveio o processo de crenulação e transposição. $O$ último episódio magmático gerou as intrusões pós-tectônicas; estas também impuseram modificaçð̃es às rochas encaixantes adjacentes. Esse episódio teria promovido reaquecimento regional e, concomitantemente, parece ter-se dado o metamorfismo retrógrado generalizadamente distinguível nas litologias formadas em fácies anfibolito.

O sistema de falhamentos transcorrentes que começou a se desenvolver logo após o metamorfismo, certamente através de alívios episódicos de tensões, mostrou-se mais ativo em tempos finais do Ciclo Brasiliano acarretando a configuração de blocos que viria a sofrer modificações em tempos poss-ordovicianos mas já sob outras condiç̋̃es tectônicas.

As consideraçðes acima, ainda que com alguns problemas de seqüenciação temporal, permitem estabelecer a Tabela $\mathrm{I}$, que resume a história geológica dos dois conjuntos.

No Conjunto Costeiro e nos núcleos Zanzalá, Capivari, Evangelista de Souza e Pilóes, os tipos litológicos, as fases de migmatização e os estilos estruturais mostram que se trata de entidades diversas das acima examinadas. Consideramo-las como segmentos do substrato da faixa de dobramentos brasilianos expostos em sua zona mais interna. Esses segmentos sofreram migmatização em parte ao menos atribuivel ao Ciclo Brasiliano, bem como intrusão de corpos granitóides pós-tectônicos desse Ciclo.

No Bloco Jundiaí, os migmatitos e as rochas resistentes à migmatização parecem fazer parte de uma sequiência pré-brasiliana que foi penetrada por corpos granitoides poss-tectônicos do Ciclo Brasiliano.

CONCLUSOES O apanhado e as discussões apresentadas permitiram elaborar a Tabela I, que sintetiza a evolução magmática, metamorfica, estrutural e migmatítica das unidades brasilianas. Sobre o Bloco Jundiaí, o Gonjunto Costeiro e núcleos polimigmatizados do Bloco Juquitiba, faltam-nos dados para tecer considerações de mais detalhe.

Por fim, alguns aspectos abordados merecem ênfase aqui:

1. A característica saliente do Precambriano na região abordada é sua constituição em blocos falhados justapostos. Em termos estratigráficos, os numerosos blocos podem ser grupados em quatro conjuntos: Jundiaí, São Roque, Paranapiacaba e Costeiro. 
Tabela I - Eventos de cristalização e deformação do Precambriano na região de São Paulo
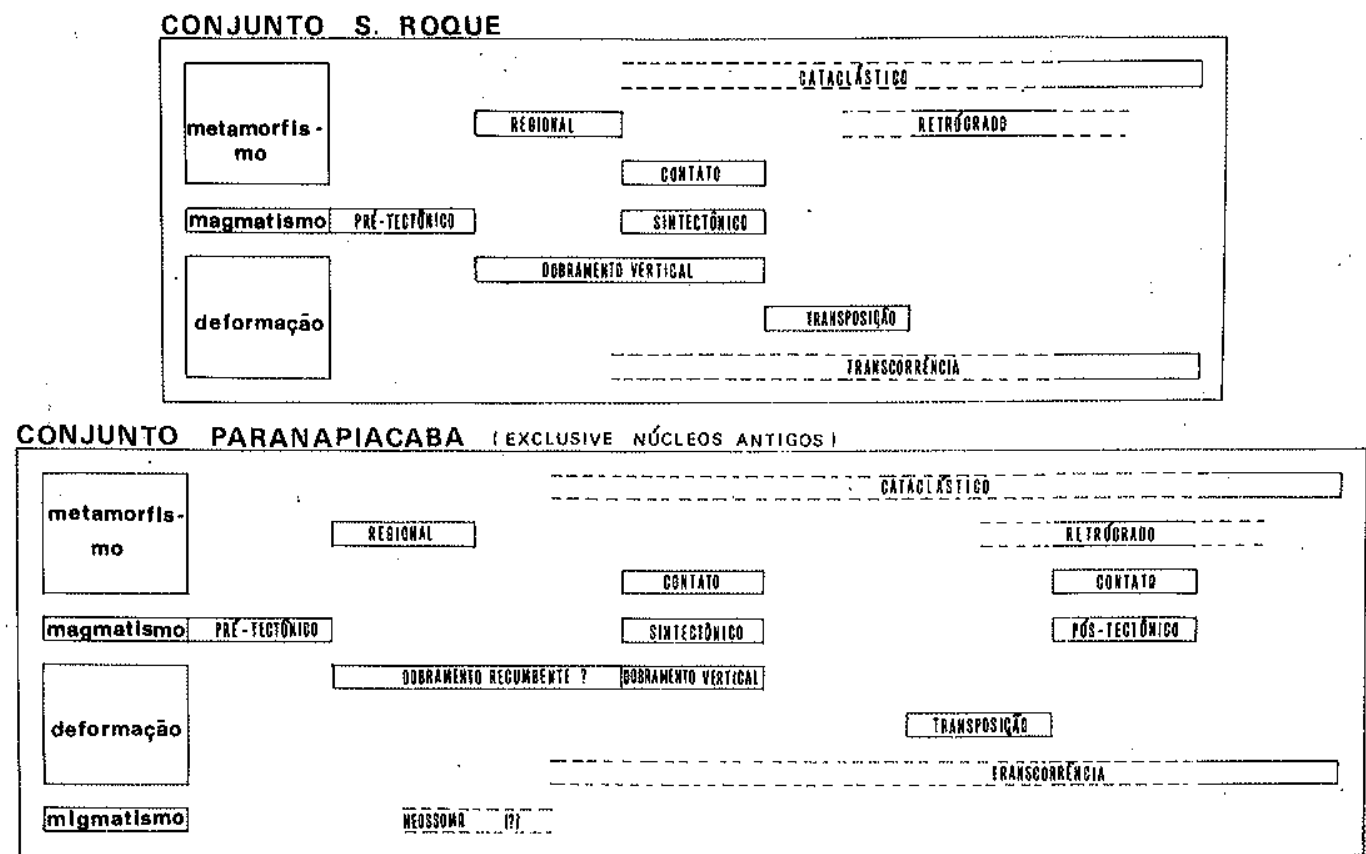

2. O Grupo São Roque é uma sequiência ectinítica, metamorfoseada em fácies xisto verde a anfibolito. Sua evolução estrutural foi relativamente simples.

3. O Grupo Açungui inclui ectinitos análogos aos do Grupo São Roque e também migmatitos; em termos litológicos, as rochas săo incluídas no Complexo Ectinítico Pilar e no Complexo Migmatítico Embu. A evolução estrutural desse grupo foi mais complexa.

4. Subdivisões estratigráficas são dificultadas pela falta de horizontes-guia nessas seqüencias metapelíticas e complexamente deformadas. Não se pode excluir a pos sibilidade de que em estudos de mais detalhe se possa compartimentar os grupos. 5. Na parte SE do Bloco Juquitiba são distinguidos os Núcleos de Zanzalá, Capivari, Pilões e Evangelista de Souza que parecem representar segmentos do embasamento da faixa de dobramentos brasiliana, expostos em meio a migmatitos pertencentes a essa faixa.

6. O Complexo Piaçagüera parece representar o embasamento pré-brasiliano que sofreu migmatização alcalina e intrusões graníticas no Ciclo Brasiliano. Os núcleos citados acima seriam constituídos por esse complexo.

7. Os falhamentos transcorrentes compõem um sistema que começou a se desenvolver logo após o metamorfismo regional da faixa brasiliana, tendo sido ativo até a estabilização da plataforma, no Siluriano.

8. Os corpos granitóides sintectônicos e tarditectônicos são parautóctonos e se constituíram na fase principal de magmatismo. Eles sofreram uma metassomatose tardia, responsável pela multiplicidade de aspectos texturais, granulométricos e composicionais das rochas.

9. O metamorfismo regional no Grupo Açungui varia de fácies xisto verde a anfibolito, de NW para SE. A migmatização foi unifásica e aumenta em intensidade nesse mesmo sentido. 
10. A fase principal de deformação foi a primeira no Conjunto São Roque; no Paranapiacaba, foi a segunda. Ambas criaram dobras com planos axiais subverticais, que são as vistas nos afloramentos e nas amostras; por causa dessa geometria, não se pôde definir até hoje o sentido de polaridade estrutural (vergência).

11. No Conjunto Costeiro, as dobras mostram forte recumbencia para $\mathrm{NW}$ e a vergência se volta nesse sentido. Todavia, as dobras visíveis em afloramentos parecem relacionar-sc a uma tectogênese pré-brasiliana.

AGRADECIMENTOS Agradecemos à Fundação de Amparo à Pesquisa do Estado de São Paulo pelo apoio que possibilitou a realização desta pesquisa. Aos Profs. Drs. Fernando F. M. de Almeida e J. M. V. Coutinho agradecemos a leitura e crítica do texto.

\section{BIBLIOGRAFIA}

AB'SABER, A. N. - 1962 - A Serra do Mar e o Litoral de Santos. Not. Geom. V (9/10): 70-77, Campinas

ALMEIDA, F.F. M. de - 1953 - Consideraçð̌es sobre a geomorfogênese da Serra de Cubatão. Bol. Paul. Ǵcogr. 15: 3-17, São Paulo

ALMEIDA, F. F. M. de - 1955 - As camadas de São Paulo e a tectônica da Serra da Cantareira. Bol. Soc. Bras. Geol. 4: 23-40, São Paulo

ALMEIDA, F. F. M. de - 1967 - Origem e evolução da Plataforma Brasileira. Bol. Div. Geol. Min. 241, DNPM, Rio de Janeiro

BETTENCOURT, J. S., FULFARO, V. J., GIRARDI, V.A. V. e PETRI, S. - 1971 - Geologia da Folha de Capão Bonito, SP. Anais XXV Congr. Bras. Geol. 1: 97, São Paulo

BRAUN, O.P.G. - 1972 - As faixas rúpteis do Brasil. XXVII Congr. Bras. Geol., Belém (mimeografado)

GORDANI, U. G. e BITTENCOURT, I. - 1967 - Determinações de idades potássio-argônio em rochas do Grupo Açungui. Anais XXI Congr. Bras. Geol. pp. 218-233, Curitiba

GORDANI, U. G,, BITTENCOURT, I., BETTENCOURT, J.S., GOMES, G. B., LELLIS, H. S., MELCHER, G. G. e MELFI, A.J. - 1971 - Geologia da Folha de Guapiara, SP. Anais XXV Congr. Bras. Geol. 1: 103, São Paulo

CORDANI, U. G., GAMPOS, A. G. R., DAVINO, A. e BJÖRNBERG, A. J. S. - 1961 - Geologia da região do Jaraguá, SP. Bol. Soc. Bras. Geol. 10: 72-91, São. Paulo

CORDANI, U. G., GIRARDI, V.A. V., GOMES, C. B., MELFI, A. J. e MELCHER, G. G. 1971 a - Geologia da Folha de Eldorado, SP. Anais XXV Gongr. Bras. Geol. 1: 103, São Paulo

CORDANI, U. G., GOMES, G. B. e GIRARDI, V.A. V. - 1963 - Rochas calcosilicatadas da região de Perus, SP. An. Ac. Bras. Gi. 35: 361-372, Rio de Janeiro

CORDANI, U. G, e KAWASHITA, K. - 1971 - Estudo geocronológico pelo método do Rb-Sr de rochas graníticas intrusivas no Grupo Açungui. Anais XXV Congr. Bras. Geol. 1: 105-110, São Paulo

COUTINHO, J. M. V. - 1953 - Petrologia da região de São Roque, SP. Fac. Fil. Gi. Letras Bol. 159 Min. 11, Univ. São Paulo

GOUTINHO, J. M. V. - 1955 - Metaconglomerado e rochas associadas no Município de São Paulo. Fac. Fil. Ci. Letras Bol. 186 Min. 13, Univ. São Paulo

COUTINHO, J. M. V. - 1971 - Precambriano ao sul da cidade de São Paulo. Roteiro da Excursð̃o n. $: 5$, XXV Congr. Bras. Geol., Bol. Esp. 2: 53-62, São Paulo

COUTINHO, J. M. V. - 1972 - Petrologia do Precambriano em São Paulo e arredores. Bol. IG 3: 5-99, Inst. Geociênc., Univ. São Paulo

DAVINO, A. - 1965 - Estudos Geológicos e Geofisicos da Serra de Araçoiaba e Arredores, Est. de São Paulo. Tese de Doutoramento. Fac. Fil. Ci. Letras, Univ. São Paulo

ELLERT, R. - 1964 - Geologia da região de Mairiporã. Tese. Fac. Fil. Gi. Letras, Univ. São Paulo 
FELIGISSIMO Jr., J. - 1968 - Carbonatitos do Estado de São Paulo. Anais Ac. Bràs. Ci. 40 (Supl.): 93-115, Rio de Janeiro

FRANCO, R. R. - 1956 - Migmatitos de textura gnáissica dos arredores de São Paulo. Bol. Soc. Bras. Geol. 5: 31-60, São Paulo

FRANCO, R.R. - 1958 - Contribuição ao conhecimento das rochas termometamórficas da Série São Roque. Fac. Fil. Gi. Letras Bol. 189 Min. 14, Univ. São Paulo

GOMES, C. B. - 1971 - Polimetamorfismo dos anfibolitos de Jaraguá, São Paulo. Tese. Inst. Geoc., Univ. São Paulo (inédito)

HASUI, Y. - 1973 - Tectônica das Folhas de Piedade e Pilar do Sul. Tese. Inst. Geociên., Univ. São Paulo

HASUI, Y. - 1975 - Evolução polifásica do Precambriano a oeste da capital paulista. Bol. IG, Inst. Geoc. Univ. São Paulo (no prelo)

HASUI, Y. - 1975a - Geologia da Folha de São Roque. Bol. IG, Inst. Geoc. Univ. São Paulo (no prelo)

HASUI, Y., CARNEIRO, C. D. R. e COIMBRA, A. M. - 1975 - The Ribeira Folded Belt. Rev. Bras. Geoc. 5: 257-266, São Paulo

HASUI, Y. e HAMA, M. - 1972 - Geocronologia do Grupo São Roque pelo método potássio-argônio. Rev. Bras. Geoc. 2: 18-24, São Paulo

HASUI, Y., PENALVA, F. e HENNIES, W. T. - 1969 - Geologia do Grupo São Roque. Anais XXIII Congr. Bras. Geol. pp. 101-134, Salvador

HASUI, Y., SADOWSKI, G. R., OBATA, O. R, GARNEIRO, G. D. R. e FUGK, G. F. - Geologia das Folhas de Itapecerica da Serra e Embu-Guaçu (inédito)

HENNIES, W. T., PENALVA, F. e HASUI, Y. - 1967 - Geologia do Precambriano a noroeste da Capital paulista. Bol. Paran. Geoc. 26: 17-18, Curitiba

HENNIES, W. T., HASUI, Y. e PENALVA, F. - 1967a - O Falhamento transcorrente de Taxaquara. Anais XXI Congr. Bras. Geol. pp. 159-168, Curitiba

KOLLERT, R., BJÖRNBERG, A.J.S. e DAVINO, A. - 1961 - Estudos preliminares de uma depressão circular na região da Golônia, Santo Amaro, São Paulo. Bol. Soc. Bras. Geol. 10: 57-77, São Paulo

LEINZ, V. e CARVALHO, A. M. - 1957 - Contribuição à Geologia da Bacia de São Paulo. Fac. Fil. Gi. Letras. Bol. 205 Geol. 15, Univ. São Paulo

MEHNERT, K. R. - 1968 - Migmatites and the origin of granitic rocks. Elsevier Publ. Co.

MELCHER, G. G., GOMES, G. B., GORDANI, U. G., BETTENCOURT, J. S., DAMASCENO, E. G., GIRARDI, V.A. V. e MELFI, A. J. - 1973 - Geologia e petrologia das rochas metamórficas e graníticas associadas do vale do Rio Ribeira de Iguape, SP e PR, Rev. Bras. Geoc. 3: 97-123, São Paulo

MELFI, A. J., BITTENCOURT, I. e CORDANI, U. G. - 1965 - Reconhecimento fotogeológico de parte do Grupo Açungui. Bragantia 24: 447-474, Campinas

PENALVA, F. e HASUI, Y. - 1970 - A intrusão granítica dos Morro Grande e Tico-Tico, Município de Caieiras, SP. An. Ac. Bras. Ci. 42 (4): 725 730, Rio de Janeiro

RIDEG, P. - 1974 - Geology and structure of a portion of the Serra do Mar in Eastern São Paulo, Brazil. Tese. State Univ. New York at Binghamton.

SADOWSKI, G. R. - 1974 - Tectônica da Serra de Cubatão, SP. Tese. Inst. Geoc., Univ. São Paulo

SUGUIO, K. - 1971 - Estudo comparativo dos sedimentos e rochas cristalinas circundantes da Bacia de São Paulo. Anais XXV Congr. Bras. Geol. 1: 141-153, São Paulo

VANDOROS, P. e FRANCO, R. R. - 1966 - Determinação de idades de granitos da região de Mogi das Cruzes, São Paulo, pelos métodos potássio-argônio e rubídio-estrôncio. An. Ac. Bras. Ci. 38: 289-292, Rio de Janeiro

VANDOROS, P. e OLIVEIRA, M. A.F. - 1969 - Geologia e petrografia da região de Taiaçupeba e arredores, São Paulo. An. Ac. Bras. Ci. 41: 181-194, Rio de Janeiro

WERNICK, E. - 1972 - A Geologia do Maciço granítico de Morungaba, Leste do Estado de São Paulo. Tese. Fac. Fil. Ci. Letras de Rio Glaro 